\title{
Effect of group size on avoidance learning in zebra fish, Brachydanio rerio (Pisces: Cyprinidae)
}

\author{
PHYLLIS E. GLEASON and PETER G. WEBER \\ Department of Biology, State University College at Oswego, Oswego, New York 13126 \\ and \\ SUZANNE P. WEBER \\ Department of Biology, Syracuse University, Syracuse, New York 13210
}

\begin{abstract}
The purpose of this study was to investigate the effect of density of fish on the rate of avoidance learning in a schooling fish. Naive adult zebra fish (Brachydanio rerio) were trained in a two-way aquatic shuttlebox, in isolation, in groups of two, or in groups of five. The number of trials to reach progressively more exacting levels of performance $(1,2,3, \ldots, 9$ consecutive correct avoidance responses on 2 successive days), was used to quantify the rate of learning for individuals in the three groups. Using this measure, individuals in groups of five reached any given level of performance in fewer trials than individuals tested alone, which in turn reached the progressive criteria in fewer trials than individuals tested in pairs. In addition, the mean latency of response to the conditioned stimulus for individuals in groups of five was significantly lower than for individuals tested alone or in groups of two by Day 3 of the experiment. The rate of learning in zebra fish schools at these densities may be due to either a balance between imitation learning and conflict-inhibition among the fish or the elicitation of different behavioral responses by shock, depending upon environmental stimuli.
\end{abstract}

Zebra fish, in the terminology of Shaw (1970), are a nonpolarized facultative schooling fish (Breder \& Halpern, 1946). In this study, zebra fish were trained individually and in groups of two and five to avoid a shock in an aquatic shuttlebox by responding to a visual stimulus. The purpose of the study was to determine if the rate of avoidance learning is densitydependent in these fish.

Schooling has been shown to be effective in predator avoidance (Neill \& Cullen, 1974; Seghers, 1974). The experimental design of the study simulates a predator-prey situation in which a school responds to the visual stimulus of the predator (see Dill, 1974a). An avoidance paradigm was used in this study because large schools may reduce predation as a result of avoidance learning by its members, as pointed out by Dill $(1973,1974 \mathrm{~b})$ using zebra fish as model prey. Schools of varying density were used because other studies in which groups of fish have

Phyllis E. Gleason's current address is: Department of Biological Sciences, State University of New York at Binghamton, Binghamton, New York 13901. Address correspondence concerning the article to Peter G. Weber, Department of Biology, State University College at Oswego, Oswego, New York 13126. We thank Helen B. Daly and James H. McCroskery for their critical reading of an earlier draft. We thank Dr. Henry Szechtman for suggesting the second explanation for slower learning in groups of two. been conditioned have shown that fish learn a task in proportion to their numbers (Greenberg, 1947; Hale, 1956; Warren, Bryant, Petty, \& Byrne, 1975; Welty, 1934; Wijffels, Thines, Dijkgraaf, \& Verheijen, 1967).

\section{METHOD}

Animals

Ninety adult zebra fish, $B$. rerio, standard length $24-34 \mathrm{~mm}$ $(\mathrm{M}=27.6 \pm 1.3 \mathrm{~mm} \mathrm{SD})$ and weight $0.19-0.26 \mathrm{~g}(\mathrm{M}=$ $0.23 \pm 0.03 \mathrm{~g} \mathrm{SD}$ ), were used in this study. The fish were experimentally naive and randomly chosen on the basis of sex and age from a stock supply obtained from dealers in Syracuse, New York. They were maintained in 60 -liter stock tanks at a density of about 0.42 fish per liter. Stock tanks were equipped with a motor-driven filter, an air stone, and a heater which maintained temperature at $28 \pm 1^{\circ} \mathrm{C}$. Light cycle was $12 \mathrm{~h}$ on, $12 \mathrm{~h}$ off; intensity at water level was $366 \mathrm{~lx}$. The fish were fed TetraMin fish food at the end of each test period.

\section{Apparatus}

The fish were conditioned in a LaFayette Instrument A-660 aquatic conditioning unit, modified with a manually raised nylon curtain between compartments. A 14-V, 0.15-A light at each end was the CS; a 4-V ac shock was the US. The CS-US cycle was controlled by a LaFayette 5500 programmer-timer. Training was conducted in a dark room with a $25-W$ red light $70 \mathrm{~cm}$ above the apparatus. The 3.5-liter conditioning apparatus was filled daily before the start of training with water from stock tanks.

\section{Experiment Design}

Fish were randomly assigned to three conditioning situations. 
In the first situation, 20 fish were conditioned individually. In the second situation, 20 fish were conditioned in 10 groups of 2 . In the last situation, 50 fish were conditioned in 10 groups of 5. Prior to training, individual fish in groups of two and five were randomly chosen to be unmarked or identified by India ink injection under the scales (Keys, 1928).

Each fish or group of fish was trained daily in randomized order for 10 trials until the highest criterion level (nine consecutive correct avoidances on 2 successive days) was reached or 100 trials were carried out.

\section{Procedure}

The fish were trained between 0800 and $1200 \mathrm{~h}$. To start a training session, the fish were placed in the apparatus and allowed 5 min habituation with the partition open and lights on. The lights were then turned off, the partition was closed, and the programmer-timer was turned on. At the onset of the CS in the subjects' compartment, the partition was raised. Fifteen seconds later, the US came on in the same compartment, lasting another $15 \mathrm{sec}$. The CS and US terminated simultaneously, making the total duration of the CS $30 \mathrm{sec}$ and the US $15 \mathrm{sec}$. At termination, the partition was closed. Trials were separated by $30 \mathrm{sec}$.

Responses of each fish trained alone or in groups were recorded as follows. If a fish responded by swimming to the opposite compartment before the onset of the US, it was scored as an avoidance; if this response occurred after the onset of the US, it was scored as an escape. Fish still in the same compartment at the termination of the CS and US were scored as giving no response and assigned a latency score of $30 \mathrm{sec}$. Latency of response from the onset of the CS was recorded manually with a stopwatch for fish trained individually. For groups, responses and latencies of each fish were recorded manually with a keyboard and Rustrak five-channel event recorder.

\section{Treatment of Data}

To determine whether ink marking affected performance, marked and unmarked individuals in the groups of two and five were compared by one-way analyses of variance after the experiment was over. These analyses showed that there was no significant effect of marking in groups of two or five on either trials to criterion levels or response latency on Days 1 to 3 , all $F(1,18)$ $\langle 1.55, \mathrm{p}\rangle .05$.

For the purpose of the main analysis, one fish was randomly selected, ignoring marking, from each of the groups of two and five after the experiment was over. Only data from these animals were considered, giving an $\mathrm{n}$ of 10 for each of these groups. This was done because the results for any given fish were not independent of other fish in the group. The $n$ for individuals trained alone was 20.

The number of trials necessary to reach the subcriteria of 1 , $2,3, \ldots, 9$ consecutive correct avoidance responses on each of 2 successive days was determined for all of the individuals and for each of the randomly selected group members. Latency to respond on each of the first $\mathbf{3 0}$ trials for which data were available for all fish was combined into 15 blocks of two trials and tabulated for each individual tested alone and each of the randomly selected group members. Two-way repeated measures analyses of variance were performed on both sets of data.

\section{RESULTS}

Figure 1 shows the rate of avoidance learning as measured by the mean number of trials to reach progressively more exacting subcriterion levels. Analysis of variance showed significant interaction between group size and criterion level, $F(16,296)=$ $10.88, \mathrm{p}<.001$, indicating different rates of learning. A test on the simple main effect of group size

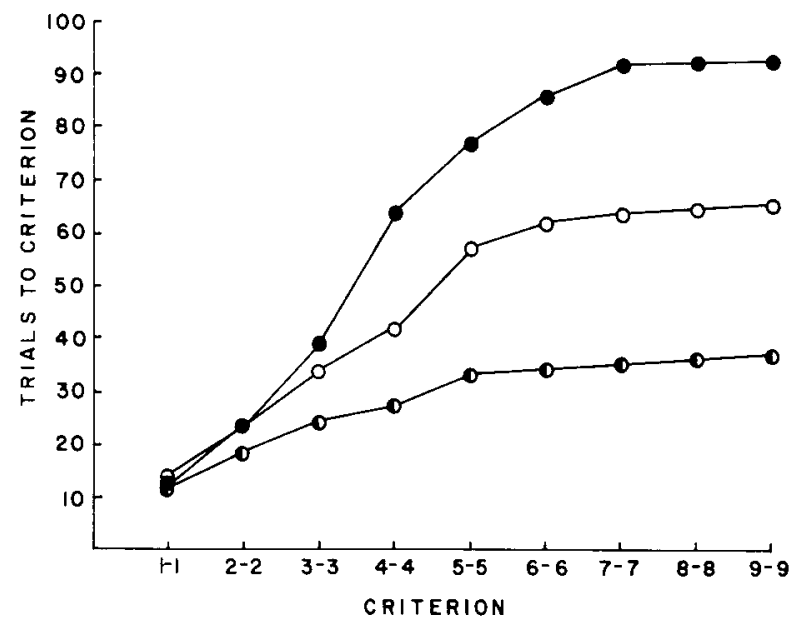

(consecutivearoldances on two successive days)

Figure 1. The number of trials to reach subcriteria for each group size. $\mathrm{O}_{-} \mathrm{O}$ Individuals tested alone. - - Individuals tested in groups of two. 0 Individuals tested in groups of five.

at the various subcriterion levels showed that the mean trials to subcriterion was not significantly different from the first three subcriterion levels, but was significantly different at each level thereafter. Scheffé tests demonstrated that after the first three subcriterion levels, the mean number of trials to reach subsequent subcriteria was highest for individuals trained in pairs, intermediate for fish trained individually, and lowest for individuals trained in groups of five (Table 1). These results show that individuals trained in groups of five learned the avoidance response more quickly than individuals trained alone; individuals in groups of two were slowest to learn the avoidance response.

Table 1

Mean Number of Trials to Reach Subcriteria: Summary of F Values from a Test on the Simple Main Effect of Group Size, at the Subcriterion Levels, and Scheffé Extensions

\begin{tabular}{ccccc}
\hline & \multicolumn{2}{c}{$\begin{array}{c}\text { Simple } \\
\text { Main } \\
\begin{array}{c}\text { Subcriterion } \\
\text { Levela }\end{array}\end{array}$} & $\begin{array}{c}\text { Effects } \\
\text { Tests }\end{array}$ & \multicolumn{3}{c}{ Gcheffé Extensions } \\
\cline { 2 - 5 } & 5 & 1 & 2 \\
\hline $1-1$ & 0.06 & $12.70^{*}$ & $14.00^{*}$ & $13.60^{*}$ \\
$2-2$ & 0.06 & $16.90^{*}$ & $22.20^{*}$ & $22.80^{*}$ \\
$3-3$ & 2.20 & $22.30^{*}$ & $33.05^{*}$ & $38.70^{*}$ \\
$4-4$ & $13.12^{* *}$ & 28.00 & 42.25 & 64.10 \\
$5-5$ & $18.96^{* *}$ & 34.00 & 57.70 & 77.80 \\
$6-6$ & $26.18^{* *}$ & 35.00 & 62.35 & 86.50 \\
$7-7$ & $31.89^{* *}$ & 36.00 & 64.15 & 92.90 \\
$8-8$ & $31.22^{* *}$ & 37.00 & 65.10 & 93.30 \\
$9-9$ & $30.56^{* *}$ & 38.00 & 66.05 & 93.70 \\
\hline
\end{tabular}

a Subcriteria refers to the number of consecutive correct avoidance responses on 2 consecutive days. For example, subcriteria 5-5 refers to five correct responses in five consecutive trials on 2 successive days.

${ }^{b} d f=2,37$ for all F ratios.

*Means do not differ at $p>.05$.

${ }^{* *} p<.01$. 
Latency to respond was also used as a measure of avoidance learning. (A response latency less than $15 \mathrm{sec}$ was defined as an avoidance response.) The mean response latency for successive trial blocks on the first 3 days for each of the three groups is shown in Figure 2. Analyses of variance of each day separately showed no significant interaction between trial block and group size on any of the days, all $F(8,148)<0.59, p>.05$. However, a significant effect of group size was indicated on the third day, $F(2,37)$ $=8.42, \mathrm{p}<.01$. A Scheffé test on the main effect of group size showed that the mean response latency on Day 3 was significantly lower for individuals trained in groups of five than for either individuals trained alone, $p<.05$, or individuals trained in groups of two, which did not differ, $p>.05$. However, the mean response latency for individuals trained in groups of five on Day 2 and individuals trained alone on Day 3 was less than $15 \mathrm{sec}$, indicating an increase in the number of avoidance responses. Mean response latency for individuals trained in groups of two was greater than $15 \mathrm{sec}$ on all 3 days.

\section{DISCUSSION}

This experiment demonstrated that groups of two zebra fish learn an avoidance response slower than do individuals, but that groups of five are faster to learn the response than individuals or pairs of fish. These results differ from those of other similarly designed studies using different fish species and learning tasks. These studies show either a consistent increase or decrease in the rate of learning with increasing density. For example, goldfish (Carassius auratus) (Welty, 1934) and green sunfish (Lepomis cyanellus) (Greenberg, 1947; Hale, 1956) learn a maze in direct proportion to their numbers. Similarly, goldfish acquire an avoidance task faster in groups (Warren et al., 1975), and harlequin fish (Rasbora heteromorpha) (Levin, 1973) retain an avoidance task better after $24 \mathrm{~h}$ with more members in a group. Hunter and Wisby (1964) have shown that five carp are more successful at learning a net avoidance than are individuals.

On the other hand, Welty (1934) found that increasing the group size from 1 and 2 , to 4 and 10 decreased the success with which mudminnows (Umbra limi) learn to jump out of the water for food. This decrease was attributed to interference by aggression which increased with group size. Breder and Halpern (1946) were unable to induce $B$. rerio individuals to school in pairs by a punishment technique, because it led to fighting between them rather than schooling. Anthouard (1973) found that pairing a conditioned goldfish with a naive individual inhibits the rate of acquisition of an operant conditioning response with a food reward, as compared to two naive individuals. Decreased performance in a maze with increase in the

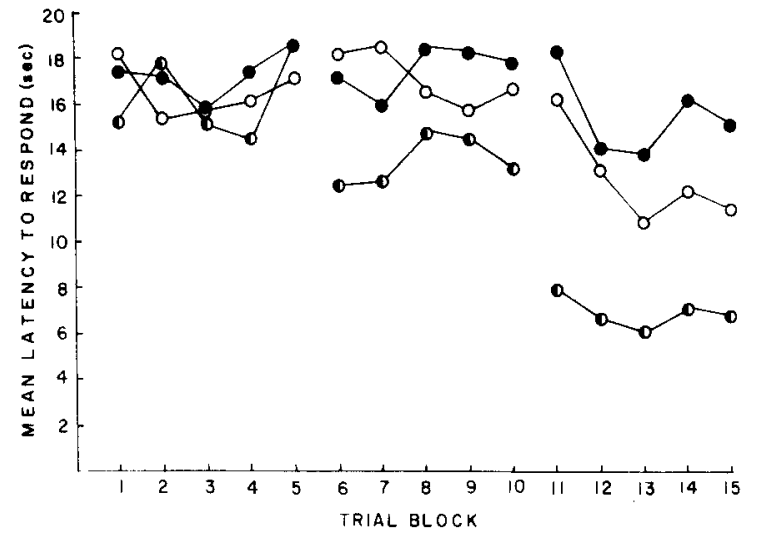

Figure 2. Mean latency to respond at trial block on first 3 days of testing for each group size. (Trial Blocks 1-5 on Day 1, 6-10 on Day 2, and 11-15 on Day 3.) $\bigcirc-O$ Individuals tested alone. - Individuals tested in groups of two. $0 \_0$ Individuals tested in groups of five.

number performing the task has also been observed in such diverse forms as cockroaches (Periplaneta americana) (Gates \& Allee, 1933) and shell parakeets (Melopsittacus undulatus) (Allee \& Masure, 1936). In both of these studies, the decrease in performance was attributed to the distractive influence of aggression as the number of individuals performing the task increased.

Aggressive encounters were not systematically recorded during the course of the present study. However, the only instances of aggression noted were among some of the groups of two. It is not known to what extent this contributed toward decreasing the overall performance of this group. It would not be surprising, however, if aggression were an interfering factor in this avoidance conditioning paradigm, since shock-induced aggression is easily elicited in most species where it has been studied (e.g., monkeys, Azrin, Hutchinson, \& Hake, 1963; cats, Ulrich, Wolff, \& Azrin, 1964; rats, Ulrich, 1966). However, if aggression were the only cause for the decreased performance of fish in pairs, as compared to individuals, it would be expected that the performance of groups of five would be similarly affected. Some other explanation is therefore required.

We begin by assuming that in a larger school there is a greater probability of including several intrinsically faster learners within the group. This should increase the groups' performance even if a few members have not yet learned the response, since the school tends to act as a whole in response to environmental stimuli. O'Connell (1960) found such a condition occurring with sardine (Sardinops caerula) schools, in which an introduced naive individual acted in perfect unison with a trained school from the first trial. Levin (1973) also found that a naive $R$. heteromorpha, separated from a conditioned school by a glass partition, would follow the trained group in the course of its avoidance in a shuttlebox. Thus, the 
poorer performance of the groups of two as compared to groups of five may be due to the lower probability of including superior performers.

However, by the same reasoning, we would expect pairs of fish to perform better than individuals, and this was not true. At least two possible explanations for this phenomenon exist. First, in the avoidance paradigm described here, a conflict inhibition may arise when only two individuals are learning the task. For an intrinsically faster learner, the conflict between the tendency to give the avoidance response and the tendency to remain with the individual which has not yet learned the response may result in poorer learning by groups of two than by individuals. Conflict-inhibition is expected to be of lesser importance in larger groups, since a variety of responses are likely to be available for imitation.

A second explanation begins with the observation that in rats, tail-shock (Caggiula, 1972) or tail-pinch (Antelman \& Szechtman, 1975) elicits different behavioral responses depending on environmental stimuli. In analogous fashion, each fish in groups of two may interpret the shock, and the concomitant agitation in the other individual, as aggression. This would interfere with learning. On the other hand, when all fish in a larger school are agitated, each individual may interpret the shock as a signal for escape and not as an attack. This then would enhance learning.

The observation that relatively larger schools learn faster than smaller schools may be one reason why small schools of fish (two or three individuals) are not often observed in nature. In nature when schooling occurs, we might expect large schools because they protect from predators due to imitation learning, among other factors. In fact, schooling fish such as roach (Leuciscus rutilus), rudd (Scardinius erythropthalmus), and nonreproductive three-spined sticklebacks (Gasterosteus aculeatus) prefer the larger of two schools in an aquarium choice situation (Keenleyside, 1955). Small schools might be selected against because slower learning in such groups would tend to make them more vulnerable to predation.

\section{REFERENCES}

Allee, W. C., \& Masure, R. H. A comparison of maze behavior in paired and isolated shell-parakeets (Melopsittacus undulatus Shaw) in a two-alley problem box. Journal of Comparative and Physiological Psychology, 1936, 22, 131-155.

Antelman, S. M., \& Szechtman, H. Tail pinch induces eating in sated rats which appears to depend on nigrostriatal dopamine. Science, 1975, 189, 731-733.

AnthouARD, M. M. Relations interindividuelles au sein d'un groupe élémentaire de Carassins (Carassius auratus, Poissons, Cyprinidés) soumis à un conditionnement opérant à renforcement alimentaire. Comptes Rendus Hebdomadaires des Séances de l'Académie des Sciences, 1973, Série D, 273, 1483-1486.
Azrin, N. H., Hutchinson, R. R., \& Hake, D. Pain-induced fighting in the squirrel monkey. Joumal of the Experimental Analysis of Behavior, 1963, 6, 620-621.

Breder, C. M., JR., \& HAlpern, F. Innate and acquired behavior affecting the aggregation of fishes. Physiological Zoology, 1946, 19, 154-190.

CAggivla, A. R. Shock-elicited copulation and aggression in male rats. Journal of Comparative and Physiological Psychology, $1972,80,393-397$.

Dill, L. M. An avoidance learning submodel for a general predation model. Oecologia, 1973, 13, 291-312.

Dill, L. M. The escape response of the zebra danio (Brachydanio rerio) I. The stimulus for escape. Animal Behaviour, 1974, 22, 711-722. (a)

Dill, L. M. The escape response of the zebra danio (Brachydanio rerio) Il. The effect of experience. Animal Behaviour, 1974, 22, 723-730. (b)

Gates, M. F., \& Allee, W. C. Conditioned behavior of isolated and grouped cockroaches on a simple maze. Journal of Comparative and Physiological Psychology, 1933, 15, 331-358.

GREENBERG, B. Some relations between territory, social hierarchy, and leadership in the green sunfish (Lepomis cyanellus). Physiological Zoology, 1947, 20, 267-299.

HalE, E. B. Social facilitation and forebrain function in maze performance of green sunfish. Lepomis cyanellus. Physiological Zoology, 1956, 29, 93-109.

Hunter, J. R., \& WISBY, W. J. Net avoidance behavior of carp and other species of fish. Journal of the Fisheries Research Boand of Canada, 1964, 21, 613-633.

KeEnleyside, M. H. A. Some aspects of the schooling behavior of fish. Behaviour, 1955, 8, 183-248.

KEYs, A. B. Marking fish with India ink. Science, 1928, 68, 18.

Levin, L. E. Estudio sobre el efecto de la interaccion groupal sobre el aprendizaje en peces (Rasbora heteromorpha). Acta Cientifica Venezolana, 1973, 24, 50.

Neill, S. R. Sr.J., \& Cullen, J. M. Experiments on whether schooling by their prey affects the hunting behaviour of cephalopods and fish predators. Journal of Zoology, 1974, 172, 549-569.

O'Connell, C. P. Use of fish school for conditioned response experiments. Animal Behaviour, 1960, 8, 225-227.

SEghers, B. H. Schooling behavior in the guppy (Peocilia reticulata): An evolutionary response to predation. Evolution, 1974, 28, 486-489.

ShAw, E. Schooling in fishes: Critique and review. In L. R. Aronson, E. Tobach, D. S. Lehrman, \& I. S. Rosenblatt (Eds.), Development and evolution of behavior. San Francisco: Freeman, $1970, \mathrm{Pp} .452-480$.

UlRICH, R. Pain as a cause of aggression. American Zoologist, $1966,6,643-662$.

Ulrich, R., WolfF, P. D., \& AzRin, N. H. Shock as an elicitor of intra- and inter-species fighting behavior. Animal Behaviour, $1964,12,14-15$.

Warren, J. L., Bryant, R. C., Petty, F., \& Byrne, W. L. Group training in goldfish (Carassius auratus): Effects on acquisition and retention. Journal of Comparative and Physiological Psychology, 1975, 89, 933-938.

WeltY, J. C. Experiments in group behavior of fishes. Physiological Zoology, 1934, 7, 85-127.

Wijfels, H., Thines, G., Dukgraaf, S., \& Verheijen, F. J. Apprentissage d'un labyrinthe simple par des téléostéens isolés ou groupés de l'espèce Barbus ticto (Hamilton) (Pisces, Cyprinidae) Archives Neerlandaise de Zoologie, 1967, 17, 376-402.

(Received for publication August 24, 1976 revision accepted February 22, 1977.) 